\title{
Oxazaphosphorine cytostatics: A good way to create better is to study old oxazaphosphorines
}

\author{
Georg Voelcker* \\ Institute of Biochemistry II, Goethe University Frankfurt Medical School, Germany
}

\begin{abstract}
Although Cyclophosphamide and other oxazaphosphorine cytostatics are among the oldest and most widely used drugs in cancer chemotherapy, little is known about the cause of the high antitumor activity of this class of alkylating drugs compared to other alkylating cytostatics. In the present article a new scheme for the mechanism of action of oxazaphosphorine cytostatics - based on the finding that proapoptotic 2-hydroxypropanal is formed during the enzymatic degradation of aldophosphamide - is presented. Based on this scheme, possibilities for improving the antitumor activity are discussed and illustrated with practical examples.
\end{abstract}

Cyclophosphamide (CP) is one of the most effective and most frequently used anticancer agents; but so far little is known about the reason of the relative high anti tumor activity. After hydroxylation of $\mathrm{CP}$ by the hepatic $\mathrm{P} 450$ enzyme the resulting 4-hydroxycyclophosphamide (OHCP) forms an equilibrium with his tautomeric aldehyde Aldophosphamide (ALDO). OHCP and ALDO are not cytotoxic. In vivo the tautomers OHCP and ALDO are irreversibly detoxified by aldehyde dehydrogenases. It is generally accepted that not detoxified ALDO is spontaneously decomposed to the cytotoxic alkylating phosphoreamide mustard (PAM) and the toxic byproduct acrolein. The common opinion is that PAM unfolds its cell toxicity by inhibition of cell division due to DNA alkylation. Lower activity of aldehyde dehydrogenases in tumor cells and thus higher concentration of OHCP/ALDO is considered to be the reason for the high antitumor activity of $\mathrm{CP}$. This conclusion is based on in vitro experiments in which resistance of tumor cells against $\mathrm{OHCP}$ can be reversed by inhibitors of detoxifying aldehyde dehydrogenases [1]. Under physiological conditions however the fate of OHCP / ALDO differs from its fate in vitro. OHCP and ALDO are stable compounds which only release insignificant amounts of PAM (half life of OHCP/ALDO in protein free rat serum ultra filtrate $>20 \mathrm{~h}$ ) On the contrary the half life of OHCP/ ALDO in whole rat serum was determined to be $20 \mathrm{~min}$ indicating enzymatic decomposition. The decay catalyzing enzyme was identified to be a phosphodiesterase yielding the decomposition products PAM and 3-hydroxypropanal (HPA) instead of acrolein [2] (Figure 1).

Schwartz and Waxman [3] investigated the effect of OHCP on the extrinsic and intrinsic pathways of apoptosis in tumor cells. Contrary to other anticancer drugs like doxorubicin and cisplatin [4,5] which initiate the extrinsic pathway of apoptosis, 4-OHCP initiates the intrinsic, p53 mediated pathway in response to DNA damage. From their findings Schwartz and Waxman postulated a bimodal mechanism of action of OHCP/ALDO on tumor cells. Firstly DNA of cells is damaged by alkylation by PAM and secondly damaged cells are eliminated by apoptosis.

HPA known as Reuterin is produced by Lactobacillus reuteri and submitted to the culture medium. It is intensively investigated by Iyer et al. [6] and Wu et al [7]. They showed that reuterin inhibits both the antiapoptotic proteins $\mathrm{Bcl}-2$ and the TNF dependend NF- $\kappa \mathrm{B}$ activation.
The investigations showed further that the degradation of IкBa is suppressed by the supernatant of lactobacillus reuteri cultures. Thus, by the inhibition of NF- $\mathrm{KB}$, apoptosis is enhanced comparable to the effect often seen in combination chemotherapies with $\mathrm{CP}$ which include glucocorticoids which also inhibits NF- $\kappa \mathrm{B}$. These findings known from literature together with the finding that the decomposition products of ALDO in vivo are PAM and HPA lead to the reaction sequence for the p53 dependent mechanism of action of oxazaphosphorine cytostatics shown in figure 2 .

ALDO is enzymatically decomposed to PAM and HPA. PAM causes DNA damage by alkylation. The damaged cell can either repair the alkylated DNA or initiate p53 mediated cell cycle stop in order to give the cell the opportunity to repair the damage. If this is not possible apoptosis which is amplified by HPA is induced.

What are the consequences for the improvement of oxazaphosphorine cytostatics? First of all it is necessary to bypass the hydroxylation of $\mathrm{CP}$ or other oxazaphosphorine cytostatics by liver enzymes. Hydroxylation varies individually and is not controllable. In addition toxic chloracetaldehyde is produced in an alternative pathway of p450 metabolism. Secondly it is important to cause DNA damages by the alkylating function which is not easily repairable by cell repair mechanism. Thirdly it may be possible to increase antitumor activity by formation of a stronger apoptogenic aldehyde. Substances that meet these conditions are perhydrothiazinyl-phosphamide ester (Figure 3) which spontaneously but - to avoid toxic peak concentrations - slowly hydroyze to aldophosphamide derivatives and homocysteine [8].

Toxicity tests and therapy tests in mice with Ifosfamide (IF) and these IF derivatives demonstrated a clear decrease in toxicity and a strong increase in antitumor activity in the P388 mouse leukemia

Correspondence to: Georg Voelcker, Institute of Biochemistry II, Goethe University Frankfurt Medical School, Frankfurt, Germany, Tel: +49 (0)69 6301 5652, Fax: +49 (0)696301 5577, E-mail: voelcker@biochem2.de / voelckerdr@aol.com

key words: oxazaphosphorine cytostatics, 2-hydroxypropanal, perhydrothiazinylphosphamide ester, influence of DNA damage in p53 mediated apoptosis

Received: April 07, 2017; Accepted: April 23, 2017; Published: April 26, 2017 
proteinfree rat serum ultrafiltrate

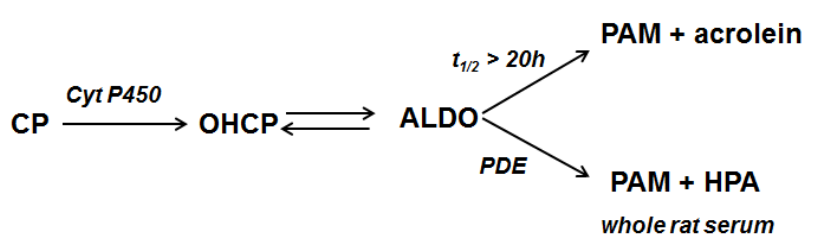

Figure 1. Cyclophosphamide (CP) is hydroxylated by liver $\mathrm{P} 450$ enzymes to 4-hydroxycyclophosphamide (OHCP) which is in equilibrium with its tautomeric form Aldophosphamide (ALDO). ALDO is either decomposed by $\beta$-elimination of acrolein to phosphoramide mustard (PAM). This reaction is catalyzed by phosphate- and bicarbonate ions. In vivo however where the concentration of these ions is too low ALDO is decomposed by phosphodiesterases (PDE) to PAM and 3-hydroxypropanal (HPA)

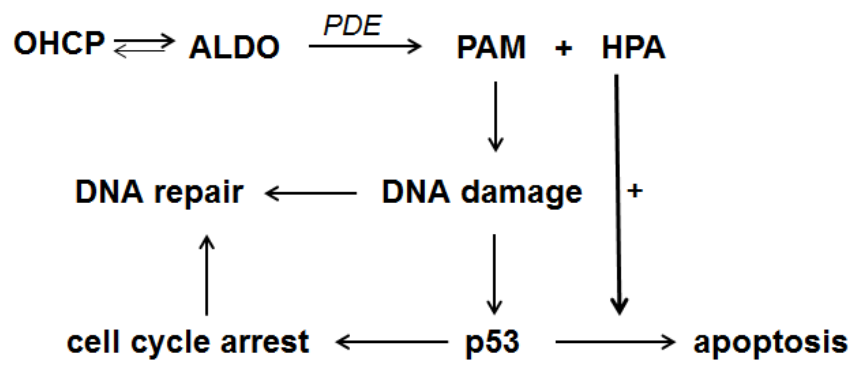

Figure 2. Reaction sequence for the mechanism of action of oxazaphosphorine cytostatics

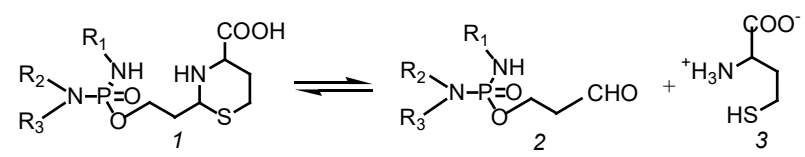

IAP: $\mathrm{R}_{1}=\mathrm{R}_{2}=-\mathrm{CH}_{2} \mathrm{CH}_{2} \mathrm{Cl}, \mathrm{R}_{3}=\mathrm{H}$; SUM-IAP: $\mathrm{R}_{1}=-\mathrm{CH}_{2} \mathrm{CH}_{2}-\mathrm{O}-\mathrm{SO}_{2} \mathrm{CH}_{3}, \mathrm{R}_{2}=-\mathrm{CH}_{2} \mathrm{CH}_{2} \mathrm{Cl}, \mathrm{R}_{3}=\mathrm{H}$

Figure 3. Hydrolysis of perhydrothiazinyl-phosphamide ester (1) to aldophosphamide (2) and homocysteine (3)

model. LD50 for acute toxicity in mice was determined to be $2.3 \mathrm{mmol} /$ $\mathrm{kg}$ for Ifosfamide (IF) compared to $6.4 \mathrm{mmol} / \mathrm{kg}$ determined for IAP. IAP is the perhydrothiazinylphosphamide ester of aldo-Ifosfamide (Figure 3). In therapy experiments in P388 tumor bearing mice with equitoxic doses of IF and IAP long time survivors (survival time
$>100 \mathrm{~d})$ were achieved with IAP but not in the experiments with IF. An almost explosive enhancement of the antitumor activity was shown in comparative therapy experiments with equimolar doses of IAP and SUM-IAP in advanced solid growing P388 tumor bearing mice. In SUM-IAP one 2-chloroethyl group of the IF structure of IAP is replaced by a mesylethyl group (Figure 3). While in the experiments with IAP only a marginal delay in tumor growth was measured, the tumor mass in the experiments with SUM-IAP was reduced below detection level [9].

The experiments clearly demonstrate improvement of antitumor activity of oxazaphosphorine cytostatics by bypassing hydroxylation by liver enzymes and optimisation of DNA alkylation.

\section{References}

1. Sladek NE, Landkamer GJ (1985) Restoration of sensitivity to oxazaphosphorines by inhibitors of aldehyde dehydrogenase activity in cultured oxazaphosphorine-resistant L1210 and cross-linking agent-resistant P388 cell lines. Cancer Res 45: 1549-1555. [Crossref]

2. Voelcker G (2017) Enzyme catalyzed decomposition of 4-hydroxycyclophosphamide. The Open Conference Proceedings Journal.

3. Schwartz PS, Waxman DJ (2001) Cyclophosphamide induces caspase 9-dependent apoptosis in 9L tumor cells. Mol Pharmacol 60: 1268-1279. [Crossref]

4. Fulda S, Susin SA, Kroemer G, Debatin KM (1998) Molecular ordering of apoptosis induced by anticancer drugs in neuroblastoma cells. Cancer Res 58: 4453-4460. [Crossref]

5. Seki K, Yoshikawa H, Shiiki K, Hamada Y, Akamatsu N, et al. (2000) Cisplatin (CDDP) specifically induces apoptosis via sequential activation of caspase-8, -3 and -6 in osteosarcoma. Cancer Chemother harmacol 45: 199-206. [Crossref]

6. Iyer C, Kosters A, Sethi G, Kunnumakkara AB, Aggarwal BB, et al. (2008) Lactobacillus reuteri promotes TNF-induced apoptosis in human myeloid leukemiaderived cells by modulation of NF-kappaB and MAPK signalling. Cell Microbiol 10: 1442-1452. [Crossref]

7. Wu M, Lee H, Bellas RE, Schauer SL, Arsura M, Katz D, et al. (1996) Inhibition of NF-kappaB/Rel induces apoptosis of murine B cells. EMBO J 15: 4682-90. [Crossref]

8. Voelcker G, Hohorst HJ (1998) Structure/activity studies with thiazolidinyl- and perhydrothiazinylphosphamide ester. J Cancer Res Clin Oncol 124: 297-300. [Crossref]

9. Voelcker G, Pfeiffer B, Schnee A, Hohorst HJ (2000) Increased antitumour activity of mesyl-I-aldophosphamide-perhydrothiazine, in vivo but not in vitro, compared to I-aldophosphamide-perhydrothiazine. J Cancer Res Clin Oncol 126: 74-78. [Crossref]

Copyright: $\odot 2017$ Voelcker G. This is an open-access article distributed under the terms of the Creative Commons Attribution License, which permits unrestricted use, distribution, and reproduction in any medium, provided the original author and source are credited. 